\title{
Assessment of Soil-Structure Interaction in Seismic Bridge Pier Analysis Using Force and Displacement Based Approaches
}

\author{
R N P Singh, Dr. Hemant Kumar Vinayak \\ $\mathrm{PhD}$ scholar, National Institute of Technology, Hamirpur, India \\ Assistant Professor, National Institute of Technology, Hamirpur, India \\ e-mail: rnpsgs@yahoo.co.in, hkvced@nith.ac.in
}

\begin{abstract}
The seismic analysis carried out assuming foundation to be perfectly rigid and bonded to the soil underneath is far from truth and therefore, the soil-structure interaction effect on the dynamic behavior of the bridge pier should be considered. The assessment of soil-structure effect on the design force generated has been estimated using Force based, Capacity Spectrum and Direct Displacement based methods considering fixed and flexible foundations. For this purpose a single cantilever bridge pier of constant diameter with varying heights has been considered for the analysis in different type of soils and earthquake zones. The study has revealed that soilStructure Interaction index is negative in some cases, especially in soft soil, implying base shear demand being greater than that of fixed base contrary to the traditional views.
\end{abstract}

Key words: Bridge Pier, Soil-Structure Interaction, Force based method Capacity Spectrum method, Direct Displacement based method.

\section{Introduction}

The bridge piers are commonly provided with spread foundations to support and to transfer the self-weight of structure as well as the load on the super structure to the ground safely. During the strong earthquake motion the satisfactory performance of major bridges are of vital concern in order to reduce losses of life and properties besides providing access to the affected areas for rescue and rehabilitation operations [1]. Though the footing is flexible, evaluation of seismic response is carried out assuming it to be perfectly rigid and firmly bonded to the soil, implying free field motion at the base of the pier [2]. Since the soil underlying the footing is neither rigid nor perfectly bonded to it, the assumption does not hold good. Therefore, the difference between the structural response evaluated assuming a perfectly rigid foundation and the actual soil foundation termed as the soil-structure interaction should be assessed along with its effect [3].

The phenomenon of soil-structure interaction arises from the fact that during earthquake motion, the incident seismic waves cause deformation in the soil and also carry the foundation 
and the super-structure with it. The motion induced in the super-structure generates inertia forces that cause dynamic stresses at the foundation which are transmitted to the soil underneath. This causes emanation of additional waves from the soil foundation interface resulting in further dynamic displacements into the foundation. As a result inertia forces are generated in the super structure. This process goes on and on simultaneously. These phenomena are known as kinematic interaction and the inertial interaction [4]. Incorporation of the soil-structure interaction involves: Kinetic interaction response of foundation embedded into the soil in free field at the soil-structure interface before excavation of soil which provides impedance for the foundation and the inertial interaction on response considering the base motions of the structure supported on impedances [5]. Various studies were conducted to evaluate the impedances of elastic half-space excited at the surface or partially embedded by concentrated, distributed or torsional sources $[4,6,7,8]$. This enabled the incorporation of soilstructure interaction in the seismic studies of structures and various simple models considering translation and rotation of foundation and the lateral motion of superstructure were proposed to study the elastic responses $[2,9,10]$. To effect economy, formation of plastic hinge is chosen at the base of pier to dissipate energy thereby adding another element to the simple elastic model to integrate inelastic effects $[3,11,12,13]$. The aspect of soil-structure interaction has also been incorporated $[14 \& 15]$ in the seismic studies by direct displacement method of design.

In some of the studies the effect of soil-structure interaction on the response of structures in comparison to fixed base has been presented in terms of the ratio of base shear flexible to the corresponding base shear of fixed footing, ratio of top displacement of flexible footing to that of fixed footing and comparison of base shear flexible to that of fixed. This provided motivation to carry out the seismic studies using force and displacement based methods to estimate the effect of soil-structure interaction of base shear demands and the results of which have been presented in this paper.

\section{Assessment of soil-structure interaction effect}

The study has been carried out on a single bridge pier considering fixed base and flexible footing (Fig.1). The work is focused on the estimation of the effect of soil-structure interaction and its variation by different analytical approaches i.e. Force based design (FBD), Capacity spectrum method (CSM) and Direct displacement based design (DDBD) with respect to changes in the height of the pier $(6 \mathrm{~m}, 9 \mathrm{~m}, 12 \mathrm{~m}, 15 \mathrm{~m}, 18 \mathrm{~m})$. The cross-section of the bridge is considered constant i.e. $1.8 \mathrm{~m}$. Although the height of the pier depends upon the site condition but as far as possible the slenderness ratio of the pier is kept below 12 [16]so that in case bridge pier fails, the failure is governed by shear rather than flexural. The seismic inertial mass at the top of pier determined from the weight of super structure, weighted live load on the span was calculated as $4277 \mathrm{KN}$. For the same pier cross-section this mass may vary depending on the span of superstructure. The reinforcement in the column is based on code design provisions. The material properties for pier considered are Modulus of elasticity of concrete and steel, $E_{c}=3.16 \times 10^{10} \mathrm{~N} / \mathrm{m}^{2}, E_{\mathrm{s}}=2 \times 10^{11} \mathrm{~N} / \mathrm{m}^{2}$ respectively, Reinforcement $\mathrm{Fe}$ 415 yield strength $f_{y}=415 \mathrm{~N} / \mathrm{mm}^{2}$, Concrete grade $=M 40$. The grade of concrete and steel used in the footing are M-20 and Fe 415.The N-values for hard, medium and soft soils were assumed 30, 20 and 10 respectively. The bearing capacity of the soils were computed based 
on different methods [17\&18] and the minimum values $300 \mathrm{kN} / \mathrm{m}^{2}, 180 \mathrm{kN} / \mathrm{m}^{2}$ and 100 $\mathrm{kN} / \mathrm{m}^{2}$ have been adopted for hard, medium and soft soils respectively.
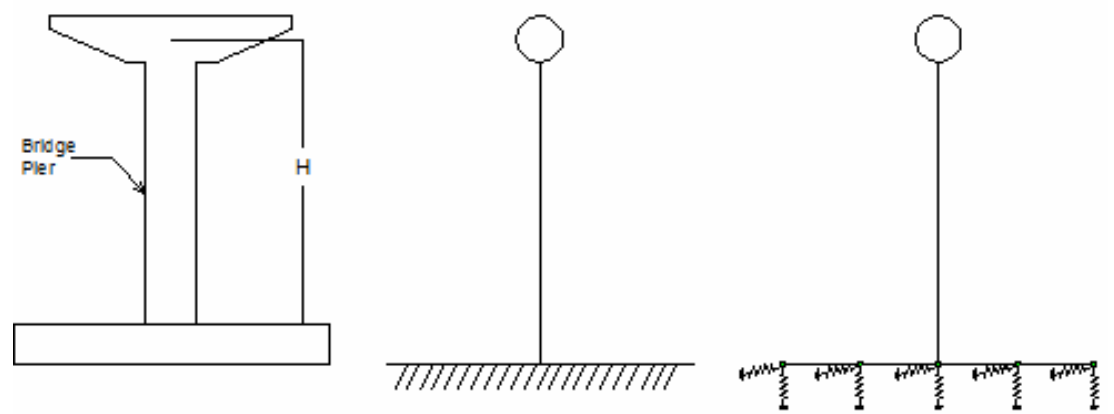

Figure 1: Bridge pier with footing with equivalent SDOF models

Based on the values of base shear obtained considering the bridge pier fixed at the base, the size footings were calculated for different height of columns in each zone and soil types using their respective bearing capacity values. Footings were considered to be supported on soils for which winkler model was adopted. The subgrade reaction values $(\mathrm{k})$ were determined using various methods $[19 \& 20]$ and the minimum values of the subgrade reaction in vertical direction were adopted as $\mathrm{kN} / \mathrm{m}^{3}, 8.3 \times 20^{2} \mathrm{kN} / \mathrm{m}^{3}$ and $\mathrm{kN} / \mathrm{m}^{3}$ for hard, medium and soft soils. Half of these values were considered in the horizontal direction.

\subsection{Force based design method}

The force based design concept transmutes empirical parameters encompassing appropriate support conditions for calculating member elastic stiffness, spectral acceleration $(\mathrm{Sa} / \mathrm{g})$ determination for calculated fundamental time period, presumed damping factor, probability of occurrence of earthquake as zone factor Z, reduction of spectral acceleration by Response reduction factor $\mathrm{R}$ for transforming structural elastic behavior into inelastic, Structural importance consideration i.e. Immediate occupancy of structure after earthquake as Importance factor I. In case the displacements are not within the specified limits the analysis is repeated with the revised member dimensions until drift criteria is satisfied. The Indian codes [21], for seismic analysis has adopted force based design that has been considered in this study. The empirical parameters adopted are - Earthquake response spectrum with damping $\xi=5 \%, \mathrm{Sa}=0.36 \mathrm{~g}, 0.24 \mathrm{~g}, 0.16 \mathrm{~g}, \mathrm{I}=1.5, \mathrm{R}=4$. To account for the soil-structure interaction the footings were divided by grids into elements which were considered to be shell element. The vertical and horizontal spring constants at each nodes were determined as the product of respective subgrade reaction values and the influence areas in the model.

\subsection{Direct Displacement Based Design}

This method is based on achieving required performance based on defined damage level. This method uses an equivalent single degree of freedom system and energy dissipation capacity is represented as equivalent viscous damping. The procedure of design uses displacement 
spectra generated for various equivalent damping factors. The displacement at four sec considered as corner period is determined as spectral displacement $\left({ }^{\Delta} \mathrm{c}\right)$. Yield curvature $\left(\Phi_{\mathrm{y}}\right)$, yield displacement $\left(\Delta_{\mathrm{y}}\right)$ and design displacement $\left(\Delta_{\mathrm{d}}\right)$ are calculated from equation (2.1) (2.2) (2.4) for the given diameter (D) and height (h) of the bridge pier.

$$
\Phi_{y}=2.25 \times \varepsilon_{y} / \mathrm{D}
$$

where, ${ }^{\boldsymbol{\varepsilon}} y=$ strain in steel.

$$
\Lambda_{y}=\Phi_{y} \times \frac{\left(h+\mathrm{L}_{\mathrm{sp}}\right)^{2}}{3}
$$

where, Strain penetration length

$$
\mathrm{L}_{\mathrm{sp}}=0.22 \times \mathrm{f}_{\mathrm{ye}} \times \mathrm{d}_{\mathrm{bl}}
$$

where $f_{y}=$ yield stress in steel and $d_{b l}=$ diameter of the longitudinal steel.

$$
\Lambda_{d}=\mu \times \Lambda_{y} \text { limited to } \mathrm{e}_{\mathrm{d}} \times \mathrm{h}
$$

where, $\mu=$ assumed displacement ductility $=4, \mathrm{e}_{\mathrm{d}}=$ limiting rotation (taken as $3.5 \%$ ) drift $\mathrm{e}_{\mathrm{d}}$ at pier base $=0.035$ radian.

Corner period displacement at equivalent viscous damping $\left(\xi_{\mathrm{eq}}\right)$ is

$$
\begin{gathered}
\Lambda_{\mathrm{c}}, \xi=\Lambda_{c} \times\left[0.1 /\left(0.005+\xi_{\mathrm{eq}}\right)\right]^{0.5} \\
\xi_{\mathrm{eq}}=0.05+0.444\left(\left(\mu_{\mathrm{s}}-1\right) / \mu_{\mathrm{s}} \pi\right) \\
\mu_{\mathrm{s}}=\frac{\Lambda_{\mathrm{d}}}{\Lambda_{\mathrm{y}}}
\end{gathered}
$$

If $\Lambda_{d} \leq \Lambda_{c}, \xi$ Effective time period,

$$
\mathrm{T}_{\mathrm{e}}=4 \times \frac{\Delta_{d}}{\Delta_{c}} \xi
$$

Stiffness

$$
\mathrm{K}_{\mathrm{e}}=4 \pi^{2} \mathrm{~m} / \mathrm{T}_{\mathrm{e}}^{2}
$$

where $\mathrm{m}=$ mass of superstructure and imposed load.

And base shear

$$
\mathrm{V}_{\mathrm{b}}=\mathrm{K}_{\mathrm{e}} \times \Delta_{\mathrm{d}}
$$

If $\Delta_{d}>\Delta_{c}, \xi$ 
Any design displacement $\Delta_{\mathrm{d}}$ is assumed, say $\Delta_{\mathrm{d}}=\Delta_{\mathrm{c}}$ Calculate $\mu_{\mathrm{s}}$ and $\xi_{\text {eq }}$ from equation (2.6) and (2.7).

Then new displacement

$$
\Lambda_{\mathrm{d}, \text { new }}=\Lambda_{\mathrm{d}}\left[0.1 /\left(0.005+\xi_{\text {eq }}\right)\right]^{0.5}
$$

With new displacement, procedure is repeated till two consecutive displacements converge. Then $\mathrm{T}_{\mathrm{e}}=4 \mathrm{sec}$ and $\mathrm{K}_{\mathrm{e}}, \mathrm{V}_{\mathrm{b}}$ are calculated from equations (2.9) and (2.10). Above procedure determines the base shear for fixed base. To account for foundation flexibility, the above procedure is repeated with following modifications:

$$
\Lambda_{d}=\mu \times \Lambda_{\mathrm{y}}+\Lambda_{\mathrm{F}} \text { limited to } \theta_{\mathrm{d}} \times \mathrm{h}
$$

where $\Delta_{F}=$ horizontal pier top displacement calculated considering base shear for fixed base. Then equivalent viscous damping is calculated as

$$
\xi_{\text {eq }}=\left(\xi_{\mathrm{s}} \times \Lambda_{\mathrm{s}}+\xi_{\mathrm{F}} \Lambda_{\mathrm{F}}\right) /\left(\Lambda_{\mathrm{s}}+\Lambda_{\mathrm{F}}\right)
$$

where

$$
\Delta_{\mathrm{s}}=\Delta_{\mathrm{d}}-\Delta_{\mathrm{F}} \text { and } \mu \mathrm{s}=\Delta_{\mathrm{s}} / \Delta_{\mathrm{y}}
$$

$\left.\xi_{\mathrm{s}}=0.05+0.444\left(\mu_{\mathrm{s}}-1\right) / \mu_{\mathrm{s}} \pi\right)$

$\xi_{\mathrm{F}}=$ hysteretic and radiation damping for soil (5\%).

\subsection{Capacity Spectrum Method}

The Capacity spectrum method is a performance based nonlinear static procedure that determines performance point, a condition in which the seismic capacity as Force displacement capacity curve of the structure is equal to the seismic demand imposed on the structure as a response spectra of earthquake demand. In this method the structure is idealized as a Single Degree of Freedom (SDOF) and reduced secant stiffness and increased damping proportional to hysteretic energy are used to estimate the response spectra of non-linear system which represent the inelastic seismic demand. The increased damping occurs when earthquake ground motion drives a structure into the inelastic range resulting into a combination of inherent viscous damping and hysteretic damping. The hysteretic damping represented as equivalent viscous damping is given by

$$
\beta_{\mathrm{eq}}=\beta_{0}+0.05
$$

where, $\beta_{0}=$ hysteretic damping represented as equivalent viscous damping

$0.05=5 \%$ viscous damping inherent in the structure (assumed to be constant)

$$
\beta_{0}=1 / 4 \pi \times E_{\mathrm{D}} / \mathrm{E}_{\mathrm{SO}}
$$

$E_{D}=$ Energy dissipated by the structure in a single cycle of motion. 
$\mathrm{E}_{\mathrm{so}}=$ maximum strain energy associated with that cycle of motion,

The equivalent viscous damping obtained in the eq 3.1 is further used to determine spectral reduction factor that are used to decrease the elastic response spectrum to a reduced response spectrum with damping greater than $5 \%$ of the critical damping called as demand spectrum. The seismic demand curve was generated based upon the site location and foundation condition (seismic zone and soil type) using design response spectrum on acceleration displacement response spectrum format (called as seismic demand) [22].

The pushover curve was generated by applying step wise incremental load on the top of the bridge pier until failure. The force displacement relationship obtained are based on considered Non-linear M- $\varphi$ Plastic Hinge relation of cross-section, Plastic hinge length, Takeda Hysteretic model, material stress strain relationship, plastic hinge length and steel yield stress. The capacity curve is converted to acceleration displacement response spectra format with the equation 3.3. to . The

$$
\begin{gathered}
P F_{1}=\left[\frac{\sum_{i=1}^{N}\left(w i \Phi_{i 1} / g\right)}{\left.\sum_{i=1}^{N}\left(w i \Phi_{i 1}^{2}\right) / g\right]}\right. \\
\alpha 1=\frac{\left[\sum_{i=1}^{N}\left(w i \Phi_{i 1}\right) / g\right]^{2}}{\left[\sum_{i=1}^{N} w i / g\right]\left[\sum_{i=1}^{N}\left(w i \Phi_{i 1}^{2}\right) / g\right]} \\
S_{a}=\frac{V / W}{\alpha 1} \\
S_{d}=\frac{\Lambda_{\text {roof }}}{P F_{1} \Phi_{\text {roof }, 1}}
\end{gathered}
$$

where: PF1 = modal participation factor for the first natural mode, $\alpha 1=$ modal mass coefficient for the first natural mode., $\mathrm{w}_{\mathrm{i}} / \mathrm{g}=$ mass assigned to level $\mathrm{i}_{\text {. }}, \phi \mathrm{i}_{1}=$ amplitude of mode 1 at level i. $\mathrm{N}=$ level $\mathrm{N}$, the level which is the uppermost in the main portion of the structure., $\mathrm{V}=$ base shear., $\mathrm{W}=$ dead weight plus likely live loads, $\Delta_{\text {roof }}=$ roof displacement , $\mathrm{Sa}=$ spectral acceleration, $\mathrm{Sd}=$ spectral displacement

The performance level of the structure is then determined as the point of interaction of seismic demand and capacity curves plotted on Acceleration Displacement Response Spectrum (ADRS) format. In case of capacity spectrum method the design displacement is determined from the intersection of the capacity and the demand spectrum. From the capacity spectrum method, base shear, yield displacement, design displacement, ductility, effective period and equivalent viscous damping is obtained. To account for the soil structure interaction, the footing was modeled as mentioned in force based method. 


\section{Design Computations}

The analysis using FBD and CSM was carried out using SAP 2000 and DDBD through computational algorithm. In all the cases the response spectrum given in code with $5 \%$ damping ratio was considered. The moment curvature relation for nonlinearity of hinge was derived from the section designer incorporated in SAP-2000 [23]. The plastic hinge length was determined by the equation (2.3).

\section{Discussions of Results}

To estimate the soil-structure interaction the base shear were determined considering fixed base and flexible footing for various zones and different soil types. The results of analysis for fixed base and flexible base are presented zone-wise for hard, medium and soft soils in Fig. 2 - Fig. 7 respectively.

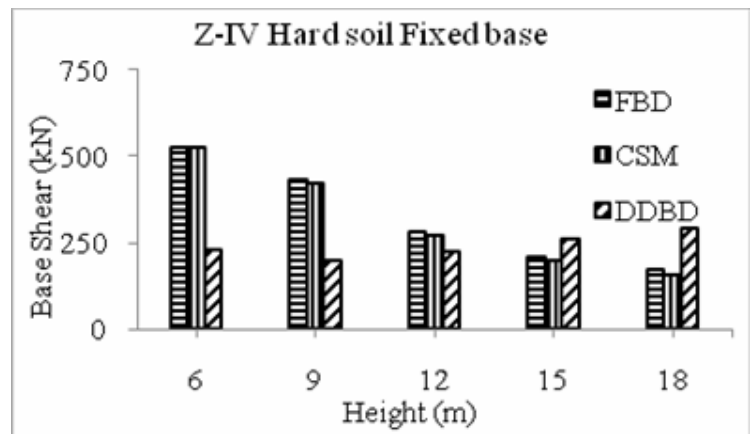

(a)

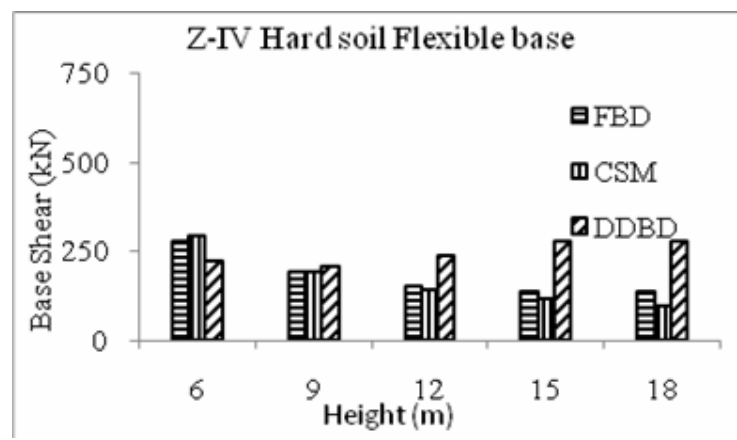

(b)

Figure 2: Base shear versus pier height for Z-IV hard soil (a) Fixed base (b) Flexible base

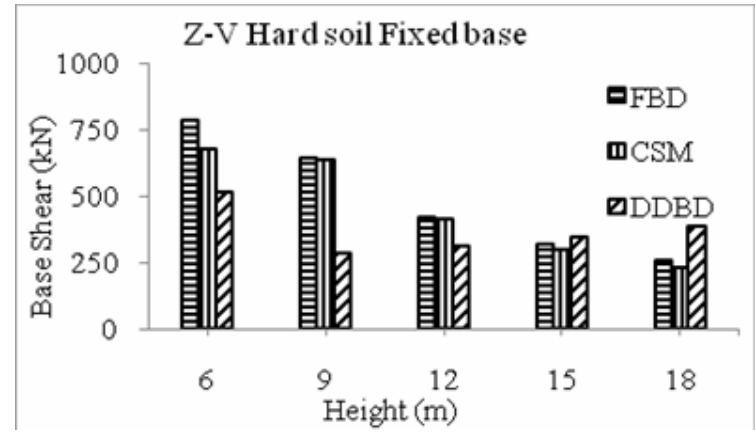

(a)

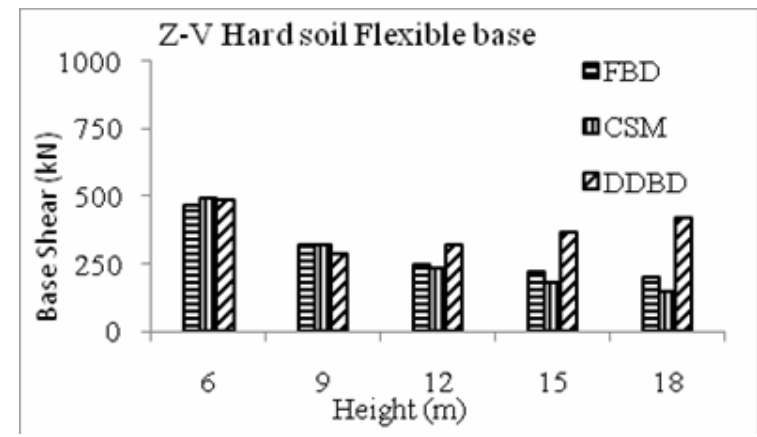

(b)

Figure 3: Base shear versus pier height for Z-V hard soil (a) Fixed base (b) Flexible base 


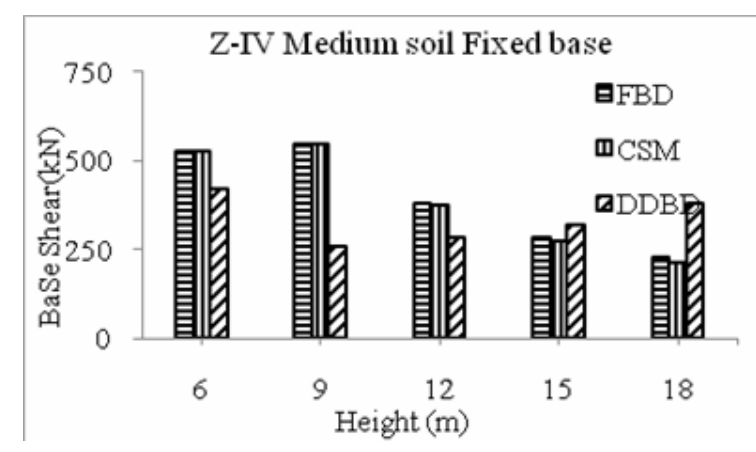

(a)

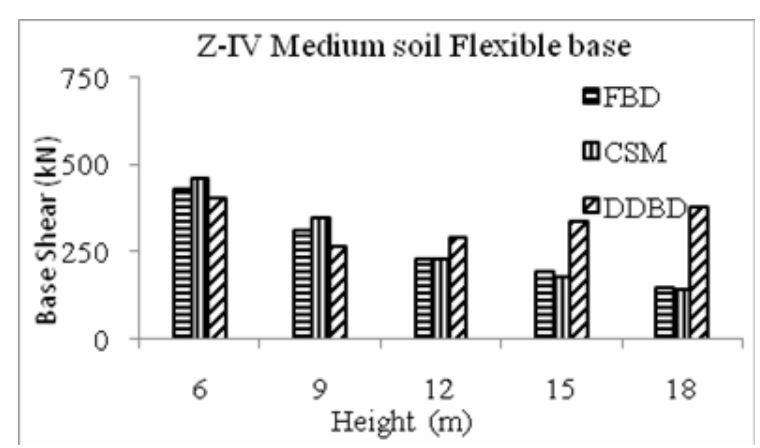

(b)

Figure 4: Base shear versus pier height for Z-IV medium soil (a) Fixed base (b) Flexible base

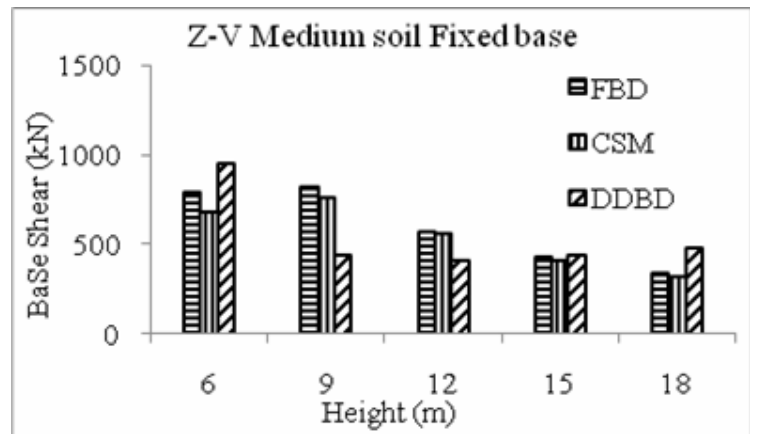

(a)

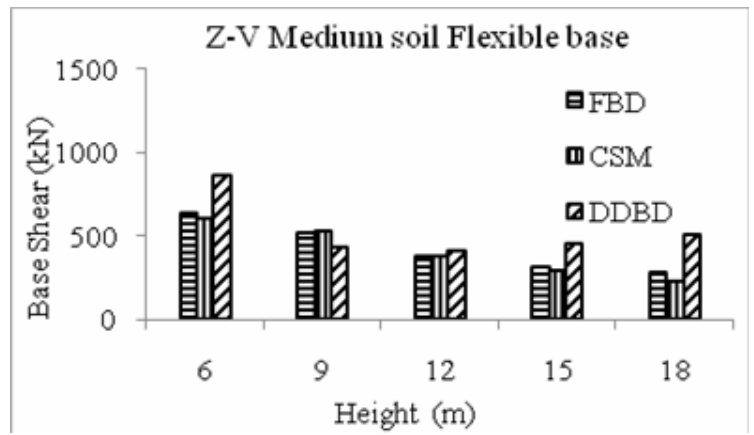

(b)

Figure 5: Base shear versus pier height for Z-V medium soil (a) Fixed base (b) Flexible base

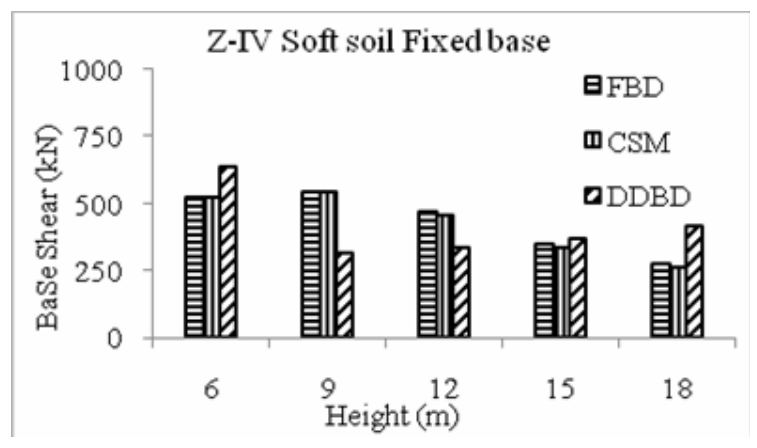

(a)

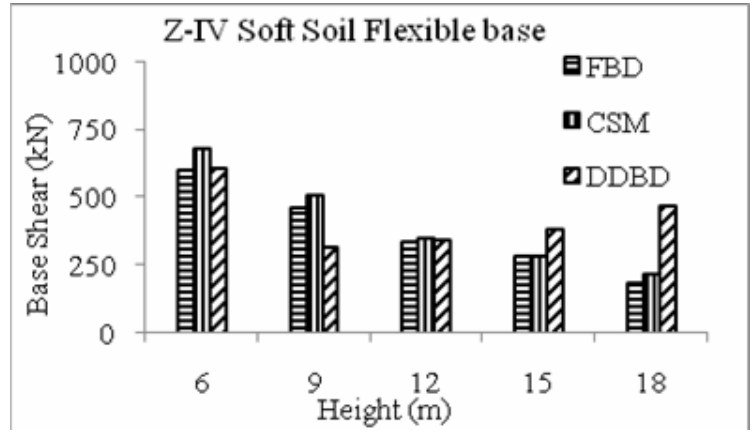

(b)

Figure 6: Base shear versus pier height for Z-IV soft soil (a) Fixed base (b) Flexible base 


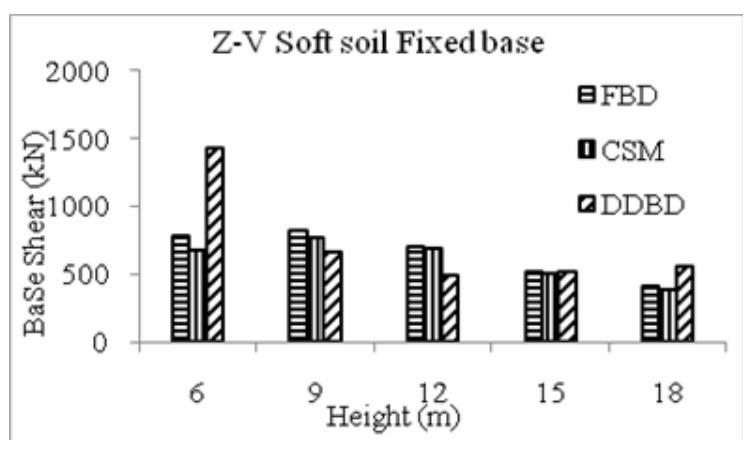

(a)

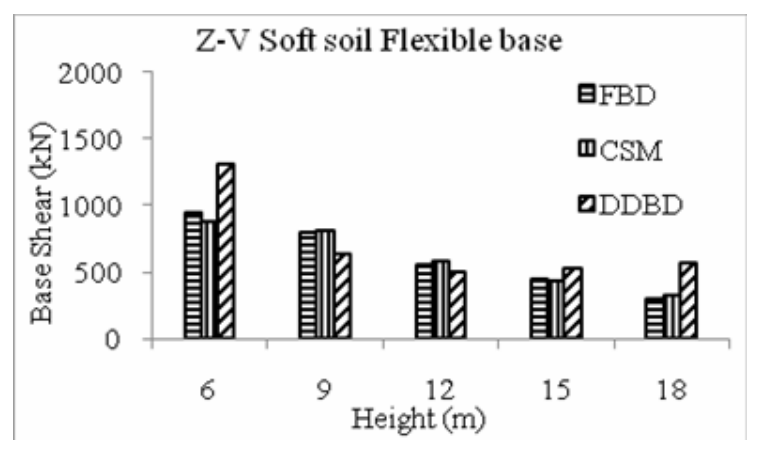

(b)

Figure 7: Base shear versus pier height for Z-V soft soil (a) Fixed base (b) Flexible base

Observation drawn from Fig.2 to Fig.7 are:

- The base shear values obtained by different method differ due to difference in approaches.

- The base shear obtained by FBD and CSM generally decrease with increase in pier height. This decrease in base shear values attributed to increasing flexibility of the bridge pier.

- $\quad$ The values of base shear obtained by FBD and CSM were comparable.

- In case of DDBD, the base shear generally decrease from $6 \mathrm{~m}$ to $9 \mathrm{~m}$ or $12 \mathrm{~m}$ pier height and then increase. The reason is that for design displacement (DD) less than corner period displacement (CPD) calculated at equivalent damping, the effective time period (ETP) is less than $4 \mathrm{sec}$. This time period increases with pier height. Further, in case of design displacement more than CPD, ETP remains at $4 \mathrm{sec}$ while the DD is iterated to rectify the design ductility. The decrease in ductility leads to increase in base shear.

- $\quad$ An important point to note is that the base shear values obtained by FBD, CSM and DDBD are quite close in the range of $12 \mathrm{~m}$ to $15 \mathrm{~m}$ pier height in case of fixed base and between $9 \mathrm{~m}$ to $12 \mathrm{~m}$ pier height in case of flexible base. In other words, it is possible to determine a pier diameter corresponding to a given a pier height when the base shear values obtained by FBD, CSM and DDBD are of the sane order.

It is noticed that the values of base shear determined by any method for any specified pier height located in any seismic zone and soil type for fixed base and flexible footing differ, which can attributed to the effect of soil structure interaction. To understand its nature, pattern of variation and magnitude, an index is required. Accordingly, the soil-structure interaction index has been defined in terms of ratio,

$$
\text { SSI Index }=\left(\mathrm{V}-\mathrm{V}^{\prime}\right) / \mathrm{V}
$$

where $\mathrm{V}=$ base shear fixed and $\mathrm{V}^{\prime}=$ base shear flexible. The values of SSI Index have been computed and presented in Fig. 8 to Fig. 10. 


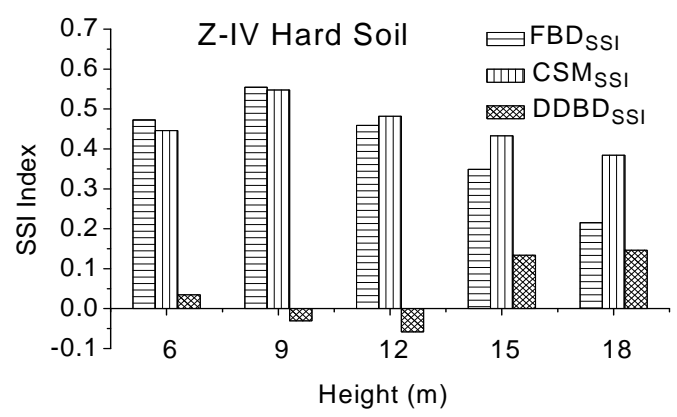

(a)

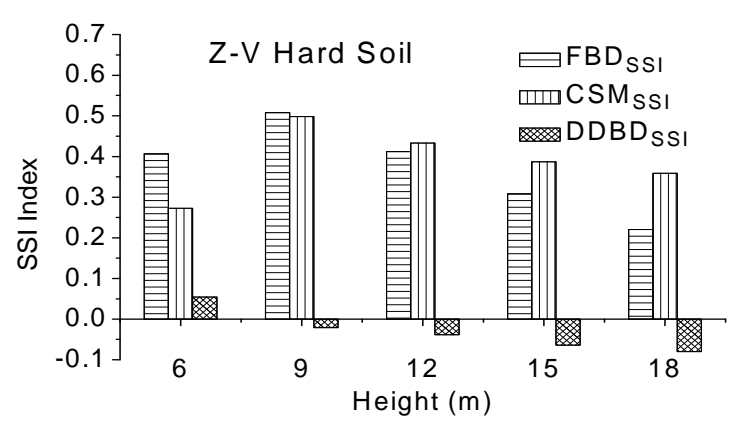

(b)

Figure 8: SSI Index versus pier height for hard soil (a) Z-IV (b) Z-V

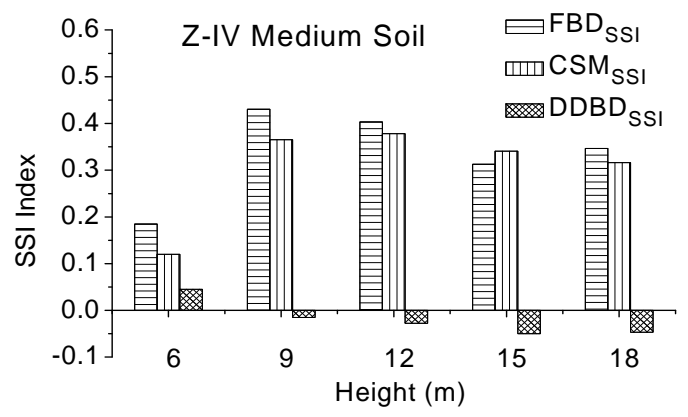

(a)

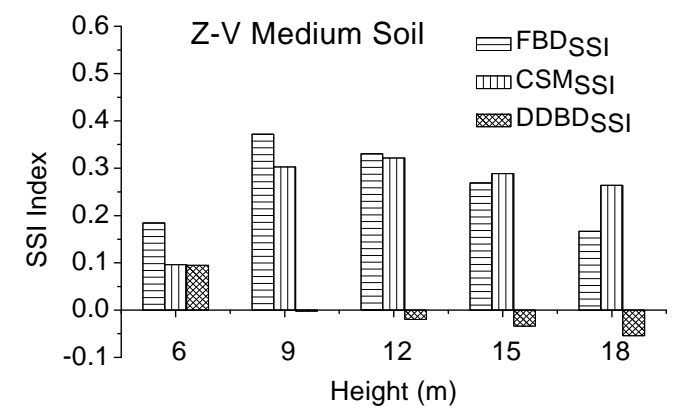

(b)

Figure 9: SSI Index versus pier height for medium soil (a) Z-IV (b) Z-V

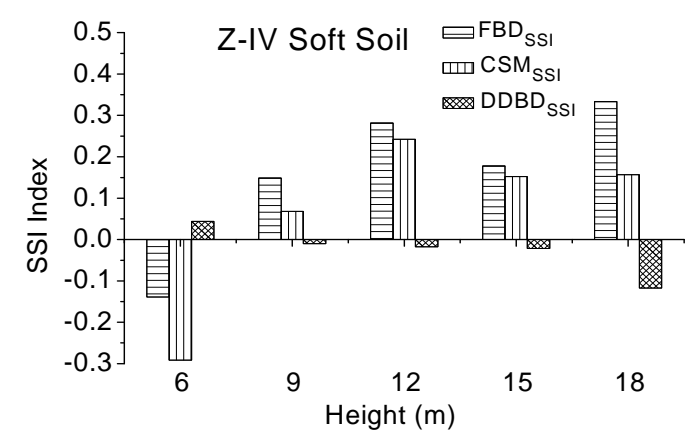

(a)

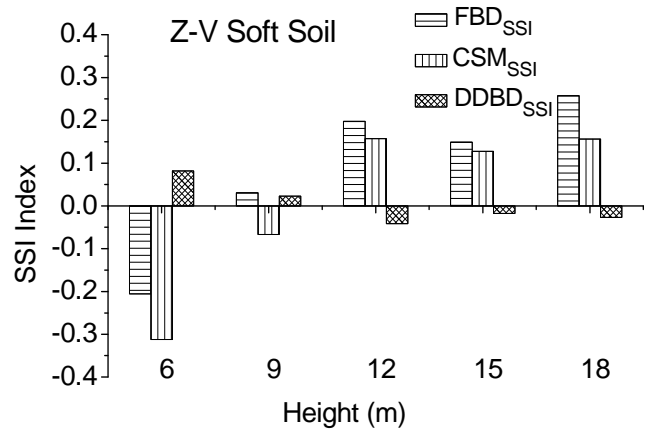

(b)

Figure 10: SSI Index versus pier height for soft soil (a) Z-IV (b) Z-V 
Observations drawn from Fig.8 to Fig.0 are the positive value of SSI Index indicates that there is a decrease in base shear values for flexible footing compared to fixed base and negative index indicates that the base shear value for flexible is greater than that of fixed base. The values of SSI Index vary from zone to zone, method to method and soil types. The effect of soil structure interaction is quite pronounced in case of FBD and CSM while it is of smaller order in case of DDBD. The pattern and the range of variation is summarized in Tab.1:

Table.1: Variation pattern of SSI Index

\begin{tabular}{|c|c|c|c|}
\hline $\begin{array}{l}\text { Soil } \\
\text { Type }\end{array}$ & $\begin{array}{l}\text { Analytical } \\
\text { Methods }\end{array}$ & According to Height of Pier & Overall Range \\
\hline \multirow[b]{3}{*}{ Hard } & FBD & \multirow{2}{*}{$\begin{array}{l}\text { The SSI Index increases from } 6 \text { to } 9 \mathrm{~m} \\
\text { height and then decreases with increasing } \\
\text { heights from } 9 \text { to } 18 \mathrm{~m} \text { for both seismic } \\
\text { Zones. }\end{array}$} & 0.22 to 0.55 \\
\hline & CSM & & 0.27 to 0.55 \\
\hline & DDBD & $\begin{array}{l}\text { The SSI Index decreases from } 6 \mathrm{~m} \text { to } 12 \mathrm{~m} \\
\text { and then increases upto } 18 \mathrm{~m} \text { in zone-IV, } \\
\text { whereas it decreases with increase in pier } \\
\text { height in zone-V. }\end{array}$ & $\begin{array}{l}-0.08 \text { to } 0.15 \text {. The } \\
\text { variation is small and in } \\
\text { most of the cases it is } \\
\text { negative showing that the } \\
\text { base shear for flexible } \\
\text { footing is greater than } \\
\text { that of fixed base. }\end{array}$ \\
\hline \multirow[b]{3}{*}{ Medium } & FBD & $\begin{array}{l}\text { The SSI Index increases from } 6 \mathrm{~m} \text { to } 9 \mathrm{~m} \text { and } \\
\text { then decreases upto } 18 \mathrm{~m} \text { pier height in both } \\
\text { seismic zones. }\end{array}$ & 0.17 to 0.47 \\
\hline & CSM & $\begin{array}{l}\text { The SSI Index increases from } 6 \mathrm{~m} \text { to } 12 \mathrm{~m} \\
\text { and then decreases upto } 18 \mathrm{~m} \text { pier height in } \\
\text { both the zones. }\end{array}$ & 0 to 0.43 \\
\hline & DDBD & $\begin{array}{l}\text { The SSI Index decreases with increase in } \\
\text { height of pier for both seismic zones. }\end{array}$ & $\begin{array}{l}-0.05 \text { to } 0.09 \text {. The } \\
\text { variation is small and in } \\
\text { most of the cases it is } \\
\text { negative showing that the } \\
\text { base shear for flexible } \\
\text { footing is greater than } \\
\text { that of fixed base. }\end{array}$ \\
\hline \multirow[t]{2}{*}{ Soft } & FBD & $\begin{array}{l}\text { The SSI Index increases with increase in } \\
\text { height of pier from } 6 \mathrm{~m} \text { to } 12 \mathrm{~m} \text { and then } \\
\text { decreases except for } 18 \mathrm{~m} \text { in both the zones. } \\
\text { The SSI is negative for } 6 \mathrm{~m} \text { in bothseismic } \\
\text { zones implying that the base shear of } \\
\text { flexible footing is greater than that with } \\
\text { fixed base. }\end{array}$ & -0.20 to 0.33 \\
\hline & CSM & $\begin{array}{l}\text { The SSI Index increases with increase in } \\
\text { pier height from } 6 \mathrm{~m} \text { to } 12 \mathrm{~m} \text { and then } \\
\text { decreases except for } 18 \mathrm{~m} \text { in both seismic } \\
\text { zones. The value of SSI Index is negative }\end{array}$ & -0.31 to 0.27 \\
\hline
\end{tabular}




\begin{tabular}{|c|c|c|}
\hline & $\begin{array}{l}\text { for } 6 \mathrm{~m} \text { in both the zones and for } 9 \mathrm{~m} \text { in } \\
\text { zone- } \mathrm{V} \text { implying that the base shear for } \\
\text { flexible footing is greater than that of fixed } \\
\text { base. }\end{array}$ & \\
\hline DDBD & $\begin{array}{l}\text { The SSI Index decreases with increase in } \\
\text { height of pier for both the zones. }\end{array}$ & $\begin{array}{l}-0.11 \text { to } 0.08 \text {. The } \\
\text { variation is small and in } \\
\text { most of the cases it is } \\
\text { negative showing that the } \\
\text { base shear for flexible } \\
\text { footing is greater than } \\
\text { that of fixed base. }\end{array}$ \\
\hline
\end{tabular}

The SSI Index decreases with increase in seismic severity except for $15 \mathrm{~m}$ and $18 \mathrm{~m}$ pier height in zone-V in hard soil where it has decreasing trend in the case of DDBD. Further SSI Index decreases with increase in seismic severity except for $18 \mathrm{~m}$ pier height in case of soft soil for FBD analysis. The average values SSI Index for FBD are 0.39, 0.30 and 0.24 and for CSM are $0.41,0.26$ and 0.04 respectively for hard, medium and soft soil. The deviation of SSI index from average values are $0.17,0.13$ for FBD and 0.14 and 0.16 for CSM for hard and medium soil respectively. The deviation of SSI index is approximately equal with both the negative and positive direction in case of hard and medium soil. However the deviation of the SSI index is skewed for soft soil towards positive index both for FBD and CSM. The effect of soil-structure interaction decreases from hard to soft soil by FBD and CSM. The variation in SSI Index is, however, very small in case of DDBD.

\section{Conclusions}

The base shear values obtained by FBD and CSM have been found to be of the same order and in general decrease with increasing pier height, while the base shear values obtained by DDBD first decrease and then increase with increasing pier height in both the cases of with and without soil structure interaction

The study has shown that it is possible to determine pier diameter corresponding to a given pier height and loading condition such that the computed base shear values by FBD, CSM and DDBD are of the same order in both the cases of with and without soil structure interaction.

The SSI Index has been found to vary with varying height of the pier, type of soils and seismic severity zones.. However the SSI index is minimal incase of DDBD and of the similar order for FBD and CSM approaches.

It has traditionally been considered that the base shear in case of flexible footing is less than that of fixed base, and hence the base shear for fixed base was considered as basis of design. However, the present study has indicated that in some cases, especially for soft soil, the base shear values for flexible footing are more than that of fixed base. The soil-structure interaction should be considered for the determination of design base shear however can neglected incase DDBD approach is adopted. 


\section{References}

[1] M. J. Pristley, R. Park \& N. K. Heng.(1979). Influence of foundation compliance on the seismic response of bridge piers. Bulletin of the New Zealand National Society for Earthquake Engineering. Volume 12 ( 1), pp. 22-34.

[2] G. D. E. Carlo, M. Dolce \& D. Liberatore. (2000). Influence of soil-structure interaction on the seismic response of bridge piers. In Twelth World Conference of Earthquake Engineering, 30 Jan - 4 Feb, pp. 1-8, Auckland New Zealand, Upper Hutt N Z NZSEE.

[3] B. M. Ciampoli \& P. E. Pinto. (1995). Effects of soil-structure interaction on inelastic seismic response of bridge piers. Journal of Structural Engineering ASCE. volume 121 (5), pp. 806814. doi.org/10.1061/ (ASCE)0733-9445(1995)121:5(806)

[4] G. Mylonakis, S. Nikolaou, \& G. Gazetas.(2006). Footings under seismic loading : Analysis and design issues with emphasis on bridge foundations. Soil Dynamics and Earthquake Engineering. Volume 26 (9), pp. 824-853. doi:10.1016/j.soildyn.2005.12.005

[5] E. Kausel. (2010). Early history of soil - structure interaction. Soil Dynamics and Earthquake Engineering. volume 30 (9), pp. 822-832. doi:10.1016/j.soildyn.2009.11.001

[6] R. J. Apsel \& J. E. Luco. (1976). Torsional Response of Rigid Embedded Foundation. Journal of Engineering Mechanics Division ASCE. Volume 102 (6), pp. 957-970.

[7] P. Srinivasulu \& C. V. Vaidyanathan. (2007). Handbook of machine foundations. (New Delhi): Tata Mcgraw-Hill company Ltd.

[8] E. Celebi, S. Firat \& I. Cankaya. (2006). Evaluation of impedance function in the analysis of foundation vibration using boundary element method, Applied Mathematics and Computation. Volume 173 (1), pp. 636-667. doi:10.1016/j.amc.2005.04.006.

[9] C. C. Spyrakos.(1990). Assessment of SSI on the longitudinal seismic response of short span bridges. Engineering Structures. Volume 12 (1), pp. 60-66. doi:10.1016/0141-0296(90)90038-T

[10] C. C. Spyrakos.(1992).Seismic behavior of bridge piers including soil-structure interaction. Computers and Structures. Volume 43 (2), pp. 373-384. doi:10.1016/0045-7949(92)90155-S

[11] P. E. Mergos \& K. Kawashima.(2005). Rocking isolation of a typical bridge pier on spread foundation. Journal of Earthquake Engineering Volume 9 (2), pp. 395-414. doi: 10.1142/ S0219455415500431

[12] W. Liu, T. C. Hutchinson, B. L. Kutter, M. Hakhamaneshi, M. A. Aschheim, \& S. K. Kunnath. (2013). Demonstration of Compatible Yielding between Soil-Foundation and Superstructure Components. Journal of Structural Engineering ASCE. Volume 139, Special Issue: NEES 2: Advances in Earthquake Engineering pp.1408-1420. doi.org/10.1061/(ASCE)ST.1943$541 X .0000637$

[13] H. Ghalibafian, R. O. Foschi, \& C. E. Ventura.(2008). Performance-based assessment of the effects of soil-structure interaction on the seismic demands of bridge piers: A proposed methodology. In Fourteenth World Conference on Earthquake Engineering. October 12-17, 2008, Beijing, China: Chinese Association of Earthquake Engineering.

[14] M. J. . Pristley, G. M. Calvi \& M. J. Kowalsky.(2007). .Displacement-Based Seismic Design of Structures. Italy: IUSS Press.

[15] P. Ni, L. Petrini, \& R. Paolucci.(2014). Direct displacement-based assessment with nonlinear soil - structure interaction for multi-span reinforced concrete bridges. Structure Infrastructure 
Engineering : Maintenance, Management, Life-Cycle Desig and Performance. Volume 10 (9), pp. 1211-1227. DOI:10.1080/15732479.2013.802813

[16] The Indian Road Congress. (2011). Code of Practice for Concrete Road Bridges. IRC: 1122011. New Delhi, India.

[17] G. Ranjan \& A. S. R. Rao.(2007). Basic and applied soil mechanics. New Delhi: New Age International.

[18] Bureau of Indian standard. (2004). Code of practice for determination of bearing capacity of shallow foundation. IS: 6403-1981. New Delhi, India.

[19] R. F. Scott.(1981). Foundation Analysis. Inc. Englewood Cliff NJ: Prentice-Hall International series in Civil Engineering.

[20] Bureau of Indian standard. (1981). Code of practice for design and construction of Raft Foundations. IS: 2950 (Part 1). New Delhi, India.

[21] Bureau of Indian Standards. (2002). Criteria for Earthquake Resistant Design of Structures, General Provisions and buildings. IS: 1893 Part1. New Delhi, India.

[22] Applied Technology Courncil. (1996). Seismic evaluation and retrofit of concrete buildings. Volume I ATC 40. California.

[23] SAP2000. Structural Analysis Programme 10.0.5. Computers and Structures Inc. Berkeley CA www.csiberkeley.com. 